08,04

\title{
Парамагнитные комплексы в кристаллах селенида цинка с примесью железа
}

\author{
(C) В.А. Важенин ${ }^{1}$, А.П. Потапов ${ }^{1}$, А.В. Фокин ${ }^{1}$, М.Ю. Артёмов ${ }^{1}$, В.И. Козловский ${ }^{2,3}$ \\ ${ }^{1}$ Уральский федеральный университет (Институт естественных наук и математики), \\ Екатеринбург, Россия \\ ${ }^{2}$ Физический институт им. П.Н. Лебедева РАН, \\ Москва, Россия \\ ${ }^{3}$ Национальный исследовательский ядерный университет „МИФИ“, \\ Москва, Россия \\ E-mail: Vladimir.Vazhenin@urfu.ru
}

(Поступила в Редакцию 10 января 2018 г.)

При $120 \mathrm{~K}$ исследован парамагнитный резонанс монокристаллов ZnSe : Fe. Определены параметры спинового гамильтониана моноклинного димерного комплекса $\mathrm{Fe}^{3+}-\mathrm{Cu}^{+}$и обнаруженного второго моноклинного центра $\mathrm{Fe}^{3+}$, возникающего в результате ассоциации иона железа с ионом $\mathrm{K}^{+}$в позиции $\mathrm{Zn}^{2+}$ или вакансией цинка. Исследовано влияние на спектр парамагнитного резонанса подсветки образцов селенида цинка синим, зеленым и красным светом.

Работа выполнена в рамках государственного задания Минобрнауки России для Уральского федерального университета (3.6115.2017/8.9) и при поддержке Программы повышения конкурентоспособности НИЯУ МИФИ.

DOI: 10.21883/FTT.2018.07.46124.005

\section{1. Введение}

Кристаллы селенида цинка, содержащие двухзарядные ионы хрома и железа, являются подходящим материалом для создания перестраиваемых лазеров среднего инфракрасного диапазона. Однако легирование этих кристаллов ионами $\mathrm{Fe}^{2+}$ и $\mathrm{Cr}^{2+}$ сопровождается появлением парамагнитных центров и в других зарядовых состояниях. Для кристаллов $\mathrm{ZnSe}: \mathrm{Fe}$ с точки зрения лазерных свойств очень важно соотношение концентраций ионов $\mathrm{Fe}^{+}$электронный спин $(S=3 / 2), \mathrm{Fe}^{2+}(S=2)$ и $\mathrm{Fe}^{3+}(S=5 / 2)$. Электронный парамагнитный резонанс (ЭПР) изолированных кубических (тетраэдрических) центров $\mathrm{Fe}^{3+}$ исследован в работах [1-3]. Кроме того, было установлено, что ионы $\mathrm{Fe}^{3+}$ в кристаллах $\mathrm{ZnSe}$, $\mathrm{ZnS}$, ZnTe образуют димерные комплексы с другими примесями (моноклинные с $\mathrm{Cu}^{+}, \mathrm{Ag}^{+}$, или $\mathrm{Li}^{+}$, локализованными в положении ближайшего катиона $[4,5]$ и имеющими симметрию $\mathrm{Cs}$, тригональные $\mathrm{c} \mathrm{As}{ }^{3-}$, заместившим ближайший анион [6]). Эти комплексы характеризуются сильно анизотропными ЭПР-спектрами, обусловленными большими начальными расщеплениями. Тетраэдрические центры $\mathrm{Fe}^{+}$в $\mathrm{ZnTe}$ после облучения светом с энергией кванта $2.25 \mathrm{eV}$ наблюдались авторами [2].

Авторы [7] в отличие от работ [4,5] исследовали в $\mathrm{ZnSe}$ ориентационное поведение положений как внутридублетных (на частоте $9156 \mathrm{MHz}$ при комнатной температуре), так и междублетных (на частоте $125.7 \mathrm{GHz}$ при температуре жидкого гелия), переходов моноклинных димерных комплексов $\mathrm{Fe}^{3+}-\mathrm{Cu}^{+}$. Полученные с учетом этих измерений параметры спинового гамиль- тониана $b_{20}, b_{21}, b_{22}$ оказались примерно в 1.3 раза больше соответствующих параметров [4,5]. Причиной этого является тот факт, что использование положений только внутридублетных переходов позволяет с хорошей точностью определить соотношение параметров тонкой структуры, но их абсолютные значения дает с большой погрешностью.

Настоящая работа посвящена исследованию ЭПР спектра монокристаллов селенида цинка, легированных железом, при $110-120 \mathrm{~K}$ и влияния на него облучения видимым светом.

\section{2. Методика измерений}

Кристаллы ZnSe имеют структуру кубического сфалерита (цинковой обманки) с пространственной группой $T_{d}^{2}(F \overline{4} 3 m)$ и параметром элементарной ячейки $0.566 \mathrm{~nm}$. Это гранецентрированная кубическая решетка, в которой заселена половина тетраэдрических пустот.

Исследуемые кристаллы ZnSe были выращены в кварцевой ампуле из паровой фазы методом физического транспорта на затравку ZnSe в атмосфере гелия с концентрацией железа примерно $10^{18} \mathrm{~cm}^{-3}$. Образцы № $2\left(\approx 8 \times 4.5 \times 4 \mathrm{~mm}^{3}\right)$ и № $3\left(\approx 6 \times 3 \times 2.5 \mathrm{~mm}^{3}\right)$, ранее использованные в работе [7], были вырезаны из одной були. Для помещения во фторопластовый бочонок (внутренний диаметр $\approx 2.5 \mathrm{~mm})$, обеспечивающий вращение в вертикальной плоскости, образец № 3 пришлось обточить.

Измерения спектров ЭПР при 110-120 К проводились на спектрометре трехсантиметрового диапазона EMX Plus Bruker в полях до $1450 \mathrm{mT}$. Угловые зависи- 


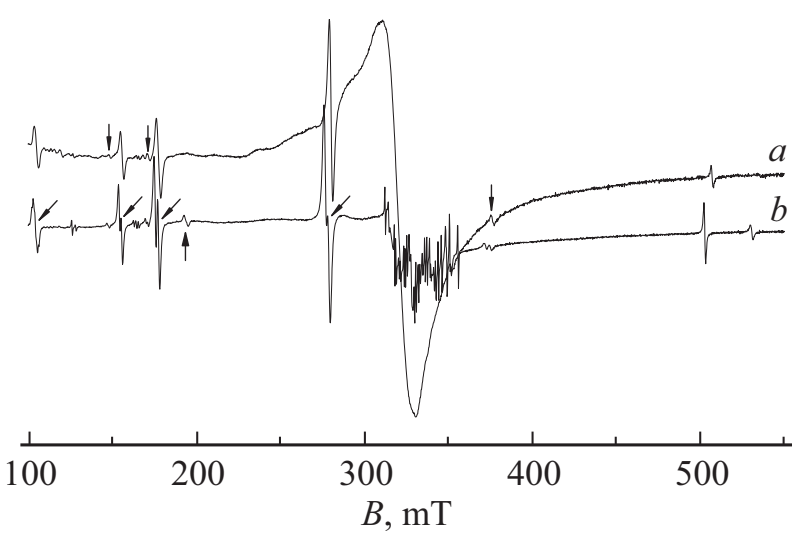

Pис. 1. Спектр ЭПР (производная спектра поглощения) ZnSe : Fe: $a$ - образец № 3 при $\mathbf{B} \| C_{4}$ и $120 \mathrm{~K}$ на частоте $9447 \mathrm{MHz}, b$ - образец № 2 вблизи $\mathbf{B} \| C_{4}$ и $110 \mathrm{~K}$ на частоте $9389 \mathrm{MHz}$. Наклонными стрелками помечены переходы моноклинного центра $\mathrm{Fe}^{3+}-\mathrm{Cu}^{+}$, верхними вертикальными сигналы второго моноклинного центра $\mathrm{Fe}^{3+}$, нижняя стрелка указывает на положение перехода тригонального центра с $S=3 / 2$. Интенсивный сигнал в центре обусловлен бочонком, в котором находится образец № 3 , а множество узких сигналов в окрестности $g \approx 2$ принадлежит переходам кубического центра $\mathrm{Mn}^{2+}$. мости спектра получены на образце № 2, приклеенном к торцу кварцевой ампулы, закрепленной в штатном одноосном автоматическом гониометре. Образец № 3 помещался во фторопластовый бочонок, расположенный на штанге гониометра, что позволяло с большей точностью реализовать ориентации: $\mathbf{B}\left\|C_{2}, \mathbf{B}\right\| C_{3}, \mathbf{B} \| C_{4}$, (где $\mathbf{B}$ - индукция магнитного поля, $C_{i}$ - оси симметрии кристалла).

Облучение образцов в резонаторе ER 4119HS спектрометра осуществлялось через штатное оптическое окно, использовались зеленые светодиоды L7113 VGC с пиковой длиной волны $525 \mathrm{~nm}(2.36 \mathrm{eV})$, синие - L7113 QBC (2.67 eV) и красные - L7113 SRC-F (1.94 eV), a также ксеноновая лампа мощностью $35 \mathrm{~W}$ с цветовой температурой $4200 \mathrm{~K}$.

\section{3. Результаты эксперимента}

При снижении температуры до $120 \mathrm{~K}$ ширина линий моноклинных центров $\mathrm{Fe}^{3+}-\mathrm{Cu}^{+}$[7] уменьшается, в результате чего сильно растет пиковая интенсивность. На фоне моноклинного спектра сигналы тригонального центра с $S=3 / 2$, также исследованного

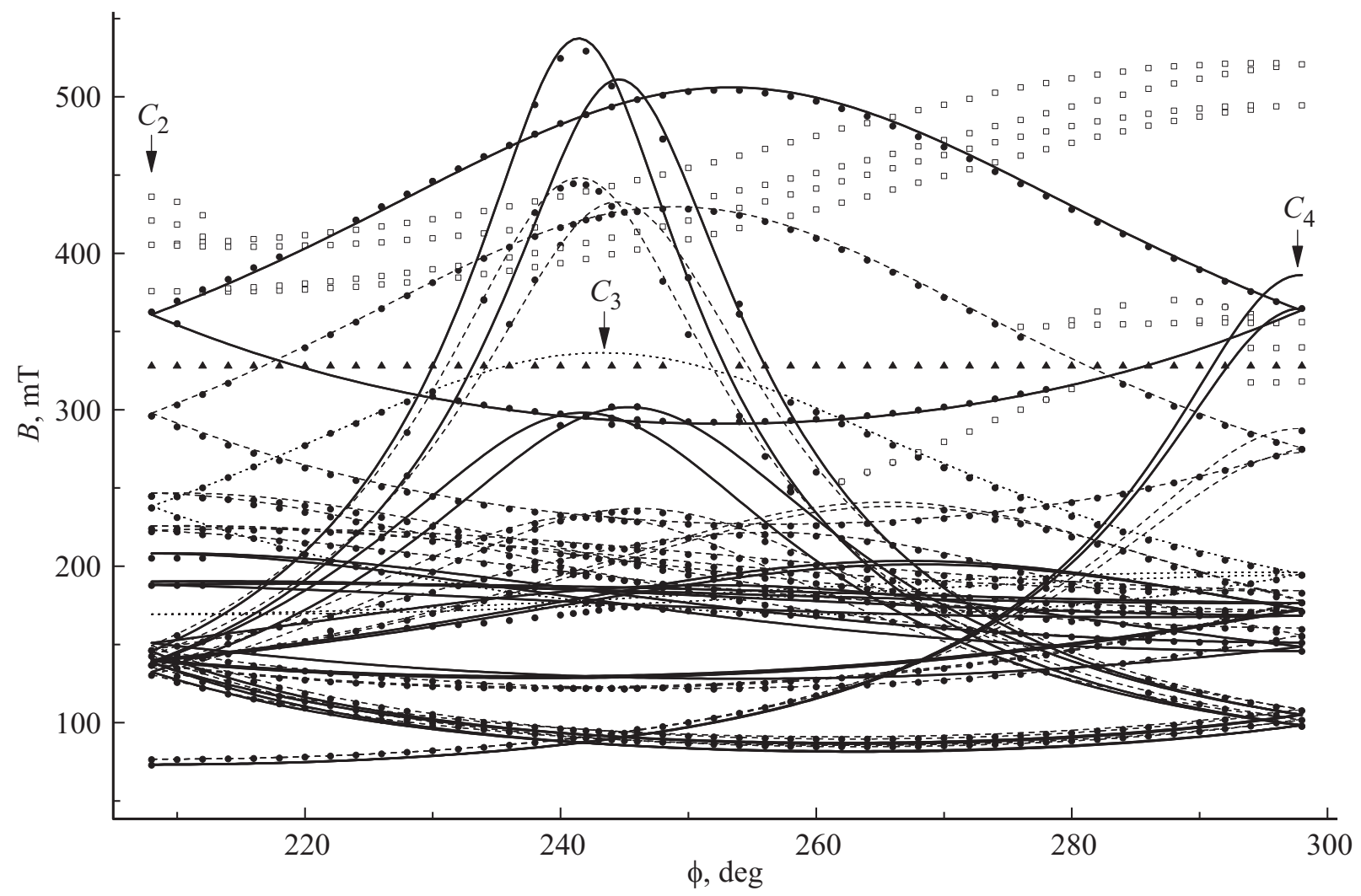

Рис. 2. Ориентационное поведение положений сигналов ЭПР $\mathrm{ZnSe}: \mathrm{Fe}$ (образец № 2) при $120 \mathrm{~K}$ и вращении магнитного поля вблизи плоскости $C_{2}-C_{3}-C_{4}$. Расчетные кривые получены для плоскости, повернутой от $C_{2}-C_{3}-C_{4}$ на $3^{\circ}$ вокруг $C_{2}$ и на $1.5^{\circ}$ вокруг $C_{4}$. Сплошные кривые - расчет для второго моноклинного центра $\mathrm{Fe}^{3+}$, штриховые - для первого, пунктир - для тригонального. Квадраты - положения не идентифицированных сигналов, треугольники - положения кубического центра $\mathrm{Fe}^{3+}$. 
Параметры спинового гамильтониана двух моноклинных центров $\mathrm{Fe}^{3+}$ в $\mathrm{ZnSe}$ при $120 \mathrm{~K}$. (Среднеквадратичное отклонение расчетных частот от экспериментальных $F(N)$ и значения $b_{n m}$ приведены в $\mathrm{MHz}, N$ - число используемых в процедуре оптимизации положений переходов)

\begin{tabular}{|c|c|c|c|c|}
\hline Параметр & $\begin{array}{c}\text { Первый } \\
\text { моноклинный } \\
\text { центр } \mathrm{Fe}^{3+}-\mathrm{Cu}^{+}\end{array}$ & $\begin{array}{c}\text { Второй } \\
\text { моноклинный } \\
\text { центр } \mathrm{Fe}^{3+}\end{array}$ & $\begin{array}{c}\text { Второй моноклинный } \\
\text { центр } \mathrm{Fe}^{3+}, \\
b_{2 m}(\text { нач. })=0.8 \cdot b_{2 m} \text { (оптим.) }\end{array}$ & $\begin{array}{c}\text { Второй моноклинный } \\
\text { центр } \mathrm{Fe}^{3+} \\
b_{2 m}(\text { нач. })=1.3 \cdot b_{2 m}(\text { оптим. })\end{array}$ \\
\hline $\begin{array}{c}g_{x} \\
g_{y} \\
g_{z} \\
b_{20} \\
b_{21} \\
b_{22} \\
b_{40} \\
b_{41} \\
b_{42} \\
b_{44} \\
F(N)\end{array}$ & $\begin{array}{c}2.045 \\
2.055 \\
2.035 \\
51820 \\
30870 \\
23140 \\
-77 \\
12(74)\end{array}$ & $\begin{array}{c}2.0499 \\
2.0476 \\
2.0323 \\
47895 \\
48779 \\
30664 \\
-228 \\
-48 \\
107 \\
591 \\
11(60)\end{array}$ & $\begin{array}{c}2.0492 \\
2.0502 \\
2.0373 \\
37685 \\
39268 \\
24205 \\
-200 \\
31 \\
51 \\
407 \\
26(60)\end{array}$ & $\begin{array}{c}2.0495 \\
2.0465 \\
2.0281 \\
66679 \\
66514 \\
42356 \\
-209 \\
166 \\
72 \\
994 \\
25(60)\end{array}$ \\
\hline
\end{tabular}

в [7], выглядят очень слабыми (рис. 1). Кроме того, спектр образца № 2, в отличие от № 3, демонстрирует довольно интенсивные сигналы кубического центра $\mathrm{Mn}^{2+}\left(g=2.0055, b_{40}=a / 2=19.7 \cdot 10^{-4} / 2 \mathrm{~cm}^{-1}\right.$, $A\left({ }^{55} \mathrm{Mn}\right)=-61.7 \cdot 10^{-4} \mathrm{~cm}^{-1}$ при 77K [8]).

Измерение угловой зависимости спектра при вращении магнитного поля примерно в плоскости $C_{2}-C_{3}-C_{4}$ (рис. 2) позволило обнаружить еще один моноклинный центр $\mathrm{Fe}^{3+}$, сигналы которого на рис. 1 помечены вертикальными стрелками. Как видно (рис. 2) этот центр демонстрирует ориентационное поведение качественно аналогичное поведению комплекса $\mathrm{Fe}^{3+}-\mathrm{Cu}^{+}$, но имеет значительно меньшую интенсивность. Кроме того, наблюдается большое количество не идентифицированных нами сигналов, угловые зависимости положений которых в больших полях приведены на рис. 2. В низких полях не идентифицированные сигналы перекрыты интенсивными переходами центров $\mathrm{Fe}^{3+}-\mathrm{Cu}^{+}$и на рис. 2 не приводятся.

Как и в работе [7] описание спектра второго моноклинного центра $\mathrm{Fe}^{3+}$ проводилось спиновым гамильтонианом в определении [9]

$$
\begin{aligned}
& H_{s p}=g \beta(\mathbf{B S})+1 / 3\left(b_{20} O_{20}+b_{21} O_{21}+b_{22} O_{22}\right) \\
& \quad+1 / 60\left(b_{40} O_{40}+b_{41} O_{41}+b_{42} O_{42}+b_{43} O_{43}+b_{44} O_{44}\right)
\end{aligned}
$$

где $g-g$-фактор, $\beta$ - магнетон Бора, $O_{n m}$ - спиновые операторы Стивенса [9], $b_{n m}$ - параметры тонкой структуры. Использовалась следующая локальная система координат: $\mathbf{Z}$ - параллельна оси $C_{3}$ кристалла, лежащей в плоскости отражения $\sigma$, рассматриваемого комплекса, $\mathbf{Y} \perp \sigma$.

Параметры гамильтониана (1), описывающего положения внутридублетных переходов $(-1 / 2 \leftrightarrow+1 / 2$ и $-3 / 2 \leftrightarrow+3 / 2)$ двенадцати одинаковых, но различно ориентированных вторых центров с симметрией $C_{S}$, приведены в таблице. Константы получены в результате компьютерной оптимизации, учитывающей положения сигналов в ориентациях $\mathbf{B}\left\|C_{2}, \mathbf{B}\right\| C_{4}$, а также данные рис. 2, где расчетная угловая зависимость получена с помощью пакета Easyspin в среде MATLAB. Согласно этим параметрам расщепления в нулевом магнитном поле составляют $131.1( \pm 1 / 2 \leftrightarrow \pm 3 / 2)$ и 190.5 $( \pm 3 / 2 \leftrightarrow \pm 5 / 2) \mathrm{GHz}$. Для сравнения в таблице приведены параметры гамильтониана центров $\mathrm{Fe}^{3+}-\mathrm{Cu}^{+}$, полученные при $120 \mathrm{~K}$ с учетом результатов измерений междублетных переходов [7], которые мало отличаются от констант при комнатной температуре.

В таблице также приведены результаты оптимизации параметров спинового гамильтониана с начальными значениями $b_{n m}$ второго ранга, отличающимися на 20-30\% от оптимальных (колонки 3 и 4). Видно, что полученные при этом наборы параметров дают существенно большее среднеквадратичное отклонение (>2 раз) расчетных данных от экспериментальных. То есть не только соотношение величин $b_{2 m}$, но и абсолютные значения параметров могут быть оценены из измерений внутридублетных переходов.

Для изменения зарядовых состояний имеющихся в кристалле примесей с целью сделать их наблюдаемыми в используемых температурном и частотном диапазонах были проведены измерения в условиях облучения светом различной длины волны.

Изменений спектра при облучении красным светодиодом и $110-120 \mathrm{~K}$ замечено не было. При возбуждении ксеноновой лампой в ориентации $\mathbf{B} \| C_{4}$ появляются два новых слабоинтенсивных спектра (рис. 3), низкополевой - бесструктурный (I) и высокополевой - со сложной структурой (II). Переход к зеленому светодиоду приводит к заметному росту указанных спектров. При облучении синим светом пиковая интенсивность спектра II увеличивается еще в четыре раза.

На рис. 4 приведен результат интегрирования ЭПР спектров, полученных в темноте и при облучении. Хоро- 


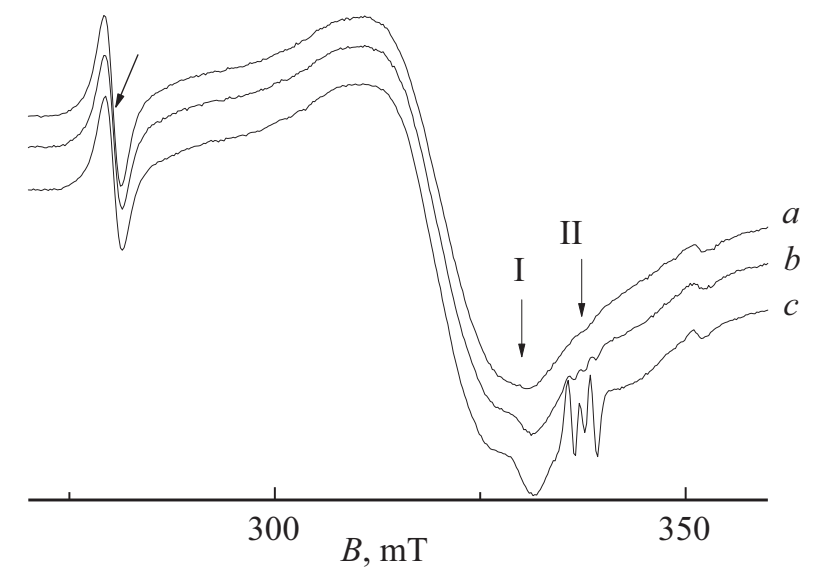

Рис. 3. Центральная часть ЭПР спектра ZnSe : Fe (образец № 3) при $120 \mathrm{~K}, \mathbf{B} \| C_{4}$ и магнитной модуляции $0.5 \mathrm{mT}$, $a-$ в темноте, $b-$ при облучении ксеноновой лампой, $c$ - зеленым светодиодом. Наклонной стрелкой помечен переход моноклинного центра $\mathrm{Fe}^{3+}-\mathrm{Cu}^{+}$.

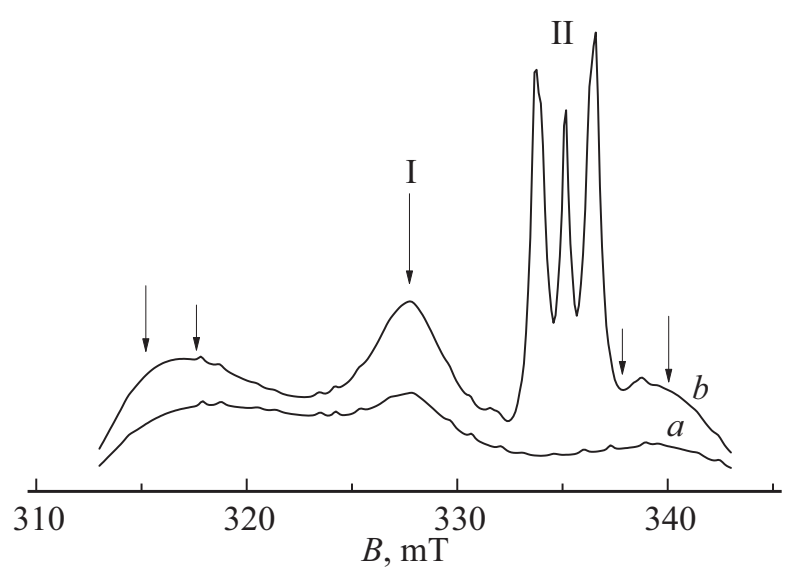

Рис. 4. Интеграл экспериментального ЭПР-спектра (образец № $\left.2,110 \mathrm{~K}, \mathbf{B} \| C_{4}\right)$. $a$ - в темноте, $b$ - при возбуждении синим светом. Стрелками показаны расчетные положения сигналов тонкой структуры кубического центра $\mathrm{Fe}^{3+}$.

шо видно, что при возбуждении кроме сигнала центра I в поле $328 \mathrm{mT}$ растет интенсивность его сателлитов, положение которых соответствует резонансным полям переходов $\pm 1 / 2 \leftrightarrow \pm 3 / 2$ и $\pm 3 / 2 \leftrightarrow \pm 5 / 2$ кубического центра $\mathrm{Fe}^{3+}$. В ориентации В $\| C_{2}$ при возбуждении зеленым и синим светом наблюдаются аналогичные интенсивные спектры I и II центров (рис. 5). Здесь сигналы тонкой структуры I центра располагаются в крыльях центрального перехода поскольку полная протяженность спектра равна $\approx 6 \mathrm{mT}$. Таким образом центр І очевидно представляет собой кубический центр $\mathrm{Fe}^{3+}(g=2.0464$, $b_{40}=a / 2=48.3 \cdot 10^{-4} / 2 \mathrm{~cm}^{-1}$ при $\left.77 \mathrm{~K}[1]\right)$, увеличивший интенсивность в результате возбуждения светом (см. рис. 5).

Высокополевой спектр II, возникающий при облучении и зарегистрированный при малой магнитной модуляции, приведен на рис. 6. Этот спектр, демонстрирующий тонкую, сверхтонкую и суперсверхтонкую структуры идеально совпадает со спектром кубического (тетраэдрического) центра $\mathrm{Cr}^{+} \mathrm{c}$ $S=5 / 2 \quad\left(g=2.0016, \quad b_{40}=a / 2=5.35 \cdot 10^{-4} / 2 \mathrm{~cm}^{-1}\right.$, $A\left({ }^{53} \mathrm{Cr}\right)=13.3 \cdot 10^{-4} \mathrm{~cm}^{-1}$ при $\left.77 \mathrm{~K}\right)$ детально исследованного автором [10]. В работе [10] сообщается о росте концентрации этих центров при облучении светом с энергией кванта, близкой к ширине запрещенной зоны.

После выключения возбуждающего света интенсивность кубических центров $\mathrm{Fe}^{3+}$ и $\mathrm{Cr}^{+}$уменьшается: при $120 \mathrm{~K}$ для центров $\mathrm{Cr}^{+}$время релаксации этого процесса порядка получаса, для $\mathrm{Fe}^{3+}$ много больше. Облучение красным светом образца с интенсивными кубическими центрами $\mathrm{Fe}^{3+}$ и $\mathrm{Cr}^{+}$, полученными в результате оптического возбуждения, приводит спектр к виду, характерному для образцов в темноте.

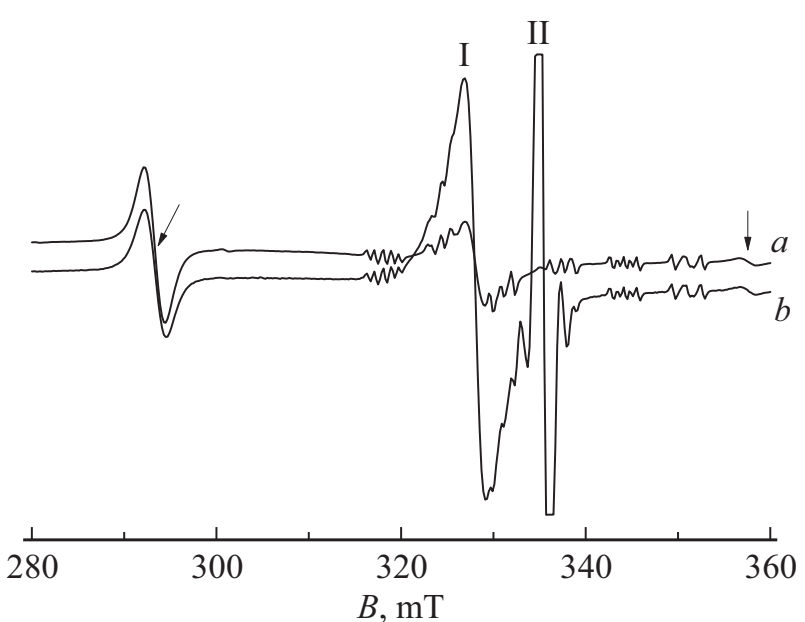

Рис. 5. ЭПР-спектр $\mathrm{ZnSe}: \mathrm{Fe}$ (образец № 2) при $120 \mathrm{~K}$ и $\mathbf{B} \| C_{2}, a-$ в темноте, $b-$ при облучении синим светодиодом. Наклонной стрелкой помечен переход моноклинного центра $\mathrm{Fe}^{3+}-\mathrm{Cu}^{+}$, вертикальной - второго моноклинного центра $\mathrm{Fe}^{3+}$. Шесть групп слабых сигналов обусловлены кубическим центром $\mathrm{Mn}^{2+}$.

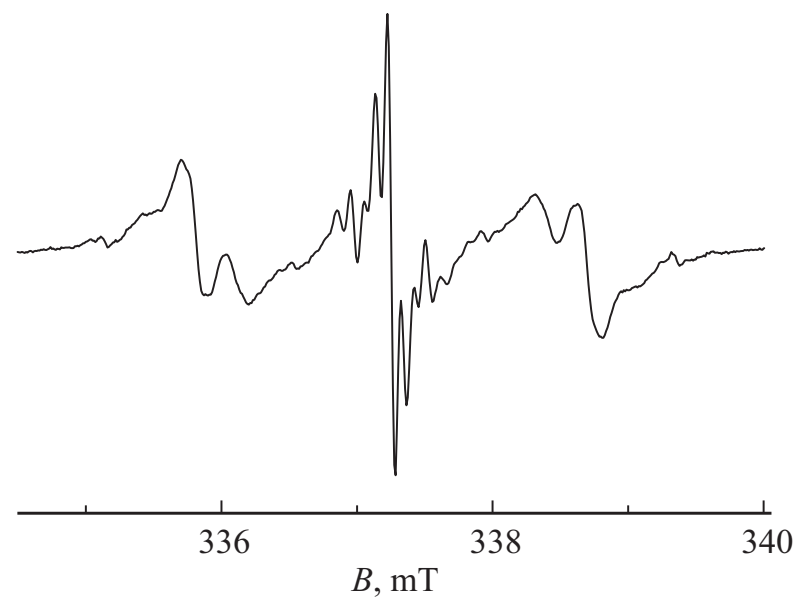

Рис. 6. Спектр кубического центра $\mathrm{Cr}^{+}(S=5 / 2)$, записанный при облучении синим светодиодом с магнитной модуляцией $0.05 \mathrm{mT}$ при $120 \mathrm{~K}$ и $\mathbf{B} \| C_{4}$. 
Отметим, что влияния облучения кристаллов $\mathrm{ZnSe}:$ Fe видимым светом на сигналы двух обсуждаемых в работе моноклинных комплексов $\mathrm{Fe}^{3+}$, тригональный центр с $S=3 / 2$, кубический спектр $\mathrm{Mn}^{2+}$, а также на не идентифицированные сигналы (см. рис. 1 и 2) не замечено.

\section{4. Обсуждение результатов}

В работах $[4,5,7]$ было обнаружено, что низкополевые ЭПР переходы комплекса $\mathrm{Fe}^{3+}-\mathrm{Cu}^{+}$в $\mathrm{ZnSe}$ имеют квартетную структуру (рис. 7), обусловленную суперсверхтонким взаимодействием (ССТВ) с ядерными спинами ${ }^{63} \mathrm{Cu}(I=3 / 2$ распространенность $69 \%)$ и ${ }^{65} \mathrm{Cu}(I=3 / 2$, $31 \%)$. При этом расщепление наблюдаемого квартета порядка величины магнитного дипольного взаимодействия, оцененного с учетом магнитных моментов ядер меди и расстояния между $\mathrm{Fe}^{3+}$ и $\mathrm{Cu}^{+}$. Аналогичные переходы второго моноклинного центра $\mathrm{Fe}^{3+}$ не демонстрируют суперсверхтонкой структуры (см. рис. 7), в связи с чем можно предположить, что компенсация избыточного заряда $\mathrm{Fe}^{3+}$, а также его низкая симметрия обеспечивается вакансией ближайшего иона $\mathrm{Zn}$.

Однако в работе [7] методом масс-спектроскопии с индуктивно-связанной плазмой было установлено наличие в кристалле примеси калия с концентрацией всего в три раза меньшей, чем меди. Несмотря на большой ионный радиус $(0.137 \mathrm{~nm}[11])$ ион $\mathrm{K}^{+}$может локализоваться в данном кристалле только в позиции $\mathrm{Zn}^{2+}$ (0.06 nm [11]) и быть (как $\mathrm{Cu}^{+}, \mathrm{Ag}^{+}, \mathrm{Li}^{+}$[4]) естественным компенсатором $\mathrm{Fe}^{3+}$. Ассоциация ионов $\mathrm{Fe}^{3+}$ и $\mathrm{K}^{+}$энергетически выгодна, то есть должна реализоваться локальная компенсация избыточного заряда $\mathrm{Fe}^{3+}$. Следовательно, обнаруженный нами второй моноклинный центр $\mathrm{Fe}^{3+}$ скорее всего представляет собой трехзарядный ион железа в позиции $\mathrm{Zn}^{2+}$ с ионом $\mathrm{K}^{+}$, заместившим ближайший ион цинка.

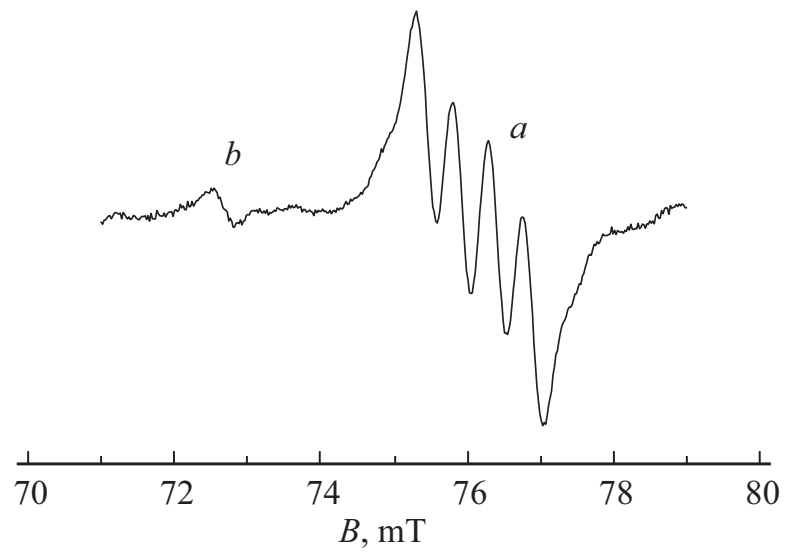

Рис. 7. ЭПР сигналы центра $\mathrm{Fe}^{3+}-\mathrm{Cu}^{+}(a)$ и второго моноклинного центра $\mathrm{Fe}^{3+}(b)$, записанные с модуляцией магнитного поля $0.1 \mathrm{mT}$ при $110 \mathrm{~K}$ и $\mathbf{B} \| C_{2}$.
Ядро изотопа ${ }^{39} \mathrm{~K}$ со спином $I=3 / 2$ и распространенностью 93\% имеет магнитный момент почти в 6 раз меньше, чем ядро иона меди. При доминировании в ССТВ c ${ }^{39} \mathrm{~K}^{+}$магнитного дипольного взаимодействия (как это реализовалось для комплекса $\mathrm{Fe}^{3+}-\mathrm{Cu}^{+}$) протяженность квартетной структуры для центра $\mathrm{Fe}^{3+}-\mathrm{K}^{+}$ должна быть примерно в 6 раз меньше, что неплохо согласуется с экспериментом (см. рис. 7).

Оптические и фотоиндуцированные ЭПР исследования изменения зарядового состояния ионов $\mathrm{Fe}$ и $\mathrm{Cr}$ в $\mathrm{ZnSe}$ при возбуждении видимым светом проведены авторами [12-15]. Было установлено, что уровень энергии $\mathrm{Cr}^{2+}$ лежит на $2.1 \mathrm{eV}$ выше края валентной зоны $\mathrm{ZnSe}$, тогда как состояние $\mathrm{Fe}^{2+}$ располагается ниже дна зоны проводимости на $2.3 \mathrm{eV}$ [12-13]. Наши наблюдения хорошо согласуются с этими результатами. Обнаруженное нами исчезновение центра $\mathrm{Cr}^{+}$при подсветке красным светодиодом также коррелирует со спектральной зависимостью скорости распада центров $\mathrm{Cr}^{+}$[13], созданных зеленой засветкой. Сходство результатов на образцах различного происхождения подтверждает то, что неконтролируемые примеси слабо влияют на оптические процессы ионов $\mathrm{Cr}$ и $\mathrm{Fe}$.

Авторы благодарны Г.С. Шакурову за помощь в ориентации кристаллов.

Измерения проведены на спектрометре трехсантиметрового диапазона Центра коллективного пользования „Современные нанотехнологии“ Уральского федерального университета.

\section{Список литературы}

[1] J. Dieleman. Philips Res. Rept. 20, 206 (1965).

[2] T.L. Estle, W.C. Holton. Phys. Rev. 150, 159 (1966).

[3] Д.Д. Крамущенко, И.В. Ильин, В.А. Солтамов, П.Г. Баранов, В.П. Калинушкин, М.И. Студеникин, В.П. Данилов, Н.Н. Ильичев, П.В. Шапкин. ФТТ 55, 234 (2013).

[4] W.C. Holton, M. de Wit, T.L. Estle, B. Dischler, J. Schneider. Phys. Rev. 169, 359 (1968).

[5] N. Sielaff, H. Nelkowski, H. Pradella, J. Sahm, K. Zink. Phys. Status Solidi B 129, K177 (1985).

[6] R.K. Watts. Phys. Rev. B 2, 1239 (1970).

[7] В.А. Важенин, А.П. Потапов, Г.С. Шакуров, А.В. Фокин, М.Ю. Артемов, В.И. Козловский, Ю.В. Коростелин, Д.С. Пыталев. ФТТ 59, 1970 (2017).

[8] R.S. Title. Phys. Rev. 131, 2503 (1963).

[9] C.А. Альтшулер, Б.М. Козырев. Электронный парамагнитный резонанс соединений элементов промежуточных групп. Наука, М. (1972). С. 121.

[10] R.S. Title. Phys. Rev. A133, 1613 (1964).

[11] R.D. Shannon. Acta Crystallogr. A32, 751 (1976).

[12] V.V. Fedorov, T. Konak, J. Dashdorj, M.E. Zvanut, S.B. Mirov. Opt. Mater. 37, 262 (2014).

[13] M. Godlewski, M. Surma, V.Yu. Ivanov, T.P. Surkova. Low Temp. Phys. 30, 891 (2004).

[14] M. Surma, M. Godlewski, T. Surkova. Phys. Rev. B 50, 8319 (1994).

[15] M. Godlewski, M. Kaminska. J. Phys. C 13, 6537 (1980).

Редактор К.В. Емцев 